\title{
Effect of the different encapsulation methods on the physicochemical and biological properties of Clitoria ternatea flowers microencapsulated in gelatine
}

\author{
${ }^{1}$ Liew, S.Y., ${ }^{1}$ Mohd Zin, Z., ${ }^{1}$ Mohd Maidin, N.M., ${ }^{2}$ Mamat, H. and ${ }^{1} *$ Zainol, M.K. \\ ${ }^{1}$ Faculty of Fisheries and Food Science, Universiti Malaysia Terengganu, 21030, Kuala Nerus, \\ Terengganu \\ ${ }^{2}$ Faculty of Food Science and Nutrition, Universiti Malaysia Sabah, 88400 Kota Kinabalu, Sabah, \\ Malaysia
}

\begin{abstract}
Article history:
Received: 15 January 2020

Received in revised form: 4 March 2020

Accepted: 7 March 2020

Available Online: 26 March 2020

\section{Keywords: \\ Clitoria ternatea flowers, Encapsulation technique, Gelatine}

\section{DOI:}

https://doi.org/10.26656/fr.2017.4(4).033

\begin{abstract}
Clitoria ternatea flowers are known as butterfly pea flowers which contain many bioactive compounds and can be found in tropical countries. However, the bioactive compounds are easily lost when exposed to various environmental conditions. Encapsulation technologies are introduced to provide maximum protection to the encapsulated bioactive compounds. The main objectives of this study were to determine the physicochemical properties of $C$. ternatea flowers encapsulated in gelatine prepared using different encapsulating methods and the microbiological properties of the best encapsulating methods for $C$. ternatea flowers with gelatine. In this study, the moisture contents for ultrasonic spray dried powders recorded the lowest $(5.94 \pm 0.44 \%)$ while samples of convection oven recorded the highest (14.33 $\pm 1.30 \%)$. However, the ultrasonic spray dried powders demonstrated the highest total flavonoid contents, but convection oven dried powders showed the lowest. The results for total anthocyanin contents were similar to total flavonoid contents. The highest encapsulation efficiency based on anthocyanin contents was found in freeze dried powders $(95.75 \pm 0.24 \%)$. These results showed the same antioxidant activity (DPPH assay) with the highest percentage inhibition of freeze dried powders and the lowest percentage inhibition of ultrasonic spray dried powders. The phytochemical functional group that revealed from Fourier Transform Infrared spectroscopic (FTIR) analysis also indicate the presence of high amount of phenolic compounds in freeze dried powders although with 'collapse building' shape with fibrillary structure. The freeze dried powder showed the highest $\mathrm{L}^{*}$ value $(45.62 \pm 0.54)$, yet ultrasonic spray dried powders highest $\mathrm{a}^{*}, \mathrm{~b}^{*}$ and $\mathrm{C}^{*}$ value. Thus, the analysis for microbial properties was carried out on freeze dried powders as freeze dryer was chosen as the best encapsulating methods. The freeze dried powders showed inhibition against gram positive and gram negative bacteria such as Bacillus cereus, Staphylococcus aureus, Escherichia coli and Salmonella enterica and fungi such as Aspergillus niger and Candida albicans. The current study demonstrated the potential of using gelatine to encapsulate technique to retain antioxidant compounds in gelatine encapsulated C. ternatea flowers. This finding provides useful information on the use of different encapsulated methods for the development of functional food products for gelatine encapsulated flowers of $C$. ternatea.
\end{abstract}

\section{Introduction}

Clitoria ternatea is known as butterfly pea or blue pea plant is a slender climbing legume with its soft hairs on its stem and long and deeper roots with ornamental flowers and these plants are distributed in tropical countries (Sivarajan and Balachandran, 1994; Collins and Grundy, 2005). C. ternatea flowers contain phenolic compounds, flavonoids, anthocyanins, saponins, alkaloids, and anthocyanidins (Kaisoon et al., 2011; Nair et al., 2015). The bioactive compounds of these flowers are however very sensitive to various changes in the environment (Pa'ee et al., 2018). In order to retain bioactive compounds, encapsulation technologies are introduced to provide maximum protection for encapsulated bioactive compounds (Talegaonkar et al., 
2016).

Encapsulation technology has been used in the food industry as a means of securing liquid and solid ingredients as an effective barrier to environmental until the release is intended. Encapsulation is the method of trapping one substance (active agents) into another substance (wall materials) (Fang and Bhandari, 2010). Most of the substances are accepted to encapsulate solids, liquids or gases or different types and properties but these substances should certify for food application as generally recognized as safe (GRAS) materials. Gelatine is natural bitterless and odorless hydrocolloid, which has received excellent attention in the food and pharmaceutical industries (Wang, 2015), because of its strong emulsifying and drying properties, such as film forming properties, relatively high glass transition temperature $(\mathrm{Tg})$, it is therefore ideal for use as both surface active agent and wall material (Karim and Bhat, 2008).

Many encapsulation methods are being used in the food industry. The benefits of using encapsulation methods are to preserve the initial nutritional value of food products, prevent oxidation and chemical modification of powder (Chen et al., 2013). Ultrasonic spray dryer differs from conventional spray dryer as the atomisation of liquid can be done through vibration using ultrasonic nozzle technology. Ultrasonic spray dryer also uses low energy to produce smaller, more uniform and more spherical droplets (Rajan and Pradit, 2001). Vacuum oven drying dries wet samples below $50^{\circ} \mathrm{C}$ under reduced pressure in order to maintain its flavour, colour and texture with less oxidation (Zielinska et al., 2013). Vacuum oven drying is faster and cheaper in encapsulating bioactive compounds with some drawbacks such as longer drying time duration and low energy consumption (Soysal and Oztekin, 2001; Arslan and Ózcan, 2010). Freeze drying is commonly used to dry heat sensitive food products and bioactive components in producing high quality dried food products with low temperature and under vacuum (Chen et al., 2013). Besides that, freeze drying is generally used to encapsulate delicate biomaterials in amorphous carbohydrate microstructure matrices. Find a way to reduce or slow down the loss of antioxidant and antimicrobial properties in plants such as C. ternatea flower powders are very essential. The purpose of this study was to investigate the physicochemical and microbiological properties of $C$. ternatea flowers embedded in gelatine, prepared using the best encapsulation methods.

\section{Material and methods}

\subsection{Sample preparation}

The flowers of $C$. ternatea were collected from Kuala Nerus, Terengganu, Malaysia. The flowers of $C$. ternatea were ground using mortar and pestle. The grounded flowers were then soaked with gelatine at a concentration of $5 \%$ relative to solid content in $100 \mathrm{~mL}$ of distilled water filtered through 3 layers of muslin cloth prior to drying.

\subsection{Drying by ultrasonic spray dryer, convection oven and freeze dryer}

The mixture of lyophilized sample and gelatine was then filtered through layers of muslin cloth to obtain fine particles prior to treatments using three different techniques namely ultrasonic spray drying, convection oven drying and freeze drying. In the first treatment, $C$. ternatea flowers were dried using ultrasonic spray dryer (YKNTECH, Kulim, Malaysia) that suited with a nozzle atomizer by keeping the outlet temperature at $100^{\circ} \mathrm{C}$ and feed flow rate at $3 \mathrm{~mL} / \mathrm{min}$ (Zainol et al., 2017). In the second treatment, $C$. ternatea flowers were dried in convection oven by setting the temperature at $80^{\circ} \mathrm{C}$ at low air pressure for $2 \mathrm{hrs}$ and in the third treatment, $C$. ternatea flowers were freeze dried at 0.8 bar for 1 week after freezing at $-80^{\circ} \mathrm{C}$ for $24 \mathrm{hrs}$ (Hamzah et al., 2013). Then, the resulted encapsulated powder was collected and stored in amber bottle at $4^{\circ} \mathrm{C}$ prior to further analysis.

\subsection{Encapsulated powder morphology structure}

The morphology structure for gelatine encapsulated C. ternatea flowers powder were carried out using scanning electron microscope (JEOL JSM-6360 LA, Tokyo, Japan) based on the method of Hau et al. (2018) with some modifications. Ten milligrams sample was mounted on SEM stubs by adhesive double-sided tape and subsequently coated with gold using Auto Fine Coater (JEOL JFC-1600) at $30 \mathrm{~mA}$ coating current. The sample was then examined at an acceleration voltage of $5 \mathrm{kV}$ with $350 \times$ magnifications.

\subsection{Colour profile}

The colour gelatine encapsulated $C$. ternatea flowers powder was measured using Minolta colorimeter (Kinoca Minolta CR/ 4, Japan). The colorimeter was calibrated by calibrate plate before analyse. The colorimeter was placed on the petri dish containing $10 \mathrm{~g}$ of $C$. ternatea flowers powder. L*(lightness), a*(redgreen), $b^{*}$ (yellow-blue) values was measured.

\subsection{Determination of functional groups}

The functional groups were determined using 
Fourier-Transform Infrared (FTIR) Spectroscopy analysis (Hau et al., 2018). A small quantity of gelatine encapsulated $C$. ternatea powder were made into pallet in the ratio of $10 \mathrm{mg}$ : $500 \mathrm{mg}$ (sample: potassium bromide, KBr (FTIR grade)). The pellet was prepared with the help of pellet maker and this pellet was placed in IR chamber and analyzed by Fourier Transform Infrared Spectroscopic (FTIR).

\subsection{Determination of moisture contents}

Moisture content in MEBP powder was measured using the method approved by AOAC International (2007).

\subsection{Determination of total flavonoid contents}

The flavonoid content of each encapsulated sample was measured based on aluminium chloride colorimetric method ( $\mathrm{Ng}$ et al., 2020). An aliquot of the sample was added to a $10 \mathrm{~mL}$ volumetric flask containing $4 \mathrm{~mL}$ of distilled water. $0.3 \mathrm{~mL}$ of $5 \% \mathrm{NaNO}_{2}$ was then added. After 5 mins, $0.3 \mathrm{~mL}$ of $10 \% \mathrm{AlCl}_{3}$ was then added. Another 5 mins, $2 \mathrm{~mL}$ of $1 \mathrm{M} \mathrm{NaOH}$ was added. The mixture volume was made up to $10 \mathrm{~mL}$ of distilled water. The solution was then mixed and absorbance was measured at $510 \mathrm{~nm}$. The total flavonoid contents were expressed as mg quercetin equivalents $(\mathrm{QE})$.

\subsection{Determination of total anthocyanin contents}

A total of $10 \mathrm{mg}$ of the extracted sample was sonicated with $5 \mathrm{~mL}$ of $50 \%$ methanol for 15 mins. Then, $0.2 \mathrm{~mL}$ extracts were diluted and mixed well with 0.8 $\mathrm{mL}$ of $50 \%$ methanol. After that, $0.3 \mathrm{~mL}$ of solution was diluted again with $4.9 \mathrm{~mL}$ of $50 \%$ methanol and mixed well. The absorbance was then measured at $530 \mathrm{~nm}$ by UV-Vis spectrophotometer (Sukwattaansinit et al., 2016).

2.9 Determination of antioxidant activity using 2, 2diphenyl-2-picrylydrazyl (DPPH assay)

Antioxidant activity of the sample powder was determined by the 2, 2-diphenyl-2-picrylydrazyl (DPPH) method of Zainol et al. (2018) with some modifications. Briefly, $0.1 \mathrm{mM}$ solution of DPPH in methanol was prepared by dissolving $1.9 \mathrm{mg}$ DPPH in $100 \mathrm{~mL}$ methanol and incubated in dark to complete the reaction. An aliquot of $4 \mathrm{~mL}$ of this solution was added with 10 $\mathrm{mL}$ of diluted extracts $(50 \mathrm{mg}$ sample in $100 \mathrm{~mL}$ distilled water), $10 \mathrm{~mL}$ of distilled water (control) and $10 \mathrm{~mL}$ of standard ascorbic acid, $\alpha$-tocopherol and Butylated hydroxyltoluene (BHT). The mixture was left to incubate in dark at room temperature for $60 \mathrm{~min}$. The absorbance at $517 \mathrm{~nm}$ was measured using UV-Vis spectrophotometer.

\subsection{Encapsulation efficiency (anthocyanin contents)}

In order to evaluate the effectiveness of microencapsulation, total anthocyanin (TA) content and surface anthocyanin (SA) contents of microparticles were determined after drying (Begum and Deka, 2017). In TA determination, $100 \mathrm{mg}$ of samples were added to 1 $\mathrm{mL}$ of distilled water was and was ground to destroy microparticles. Then, $9 \mathrm{~mL}$ of ethanol were added to the sample to allow extraction for 5 mins. In determination of SA, $100 \mathrm{mg}$ of samples were directly extracted with $10 \mathrm{~mL}$ ethanol and vortexed for $30 \mathrm{~s}$, followed by centrifugation at $3000 \mathrm{rpm}$ for 10 mins. After phase separation, the clear supernatant was collected and filtered. Anthocyanin content for TA and SA values were determined using rapid spectroscopic method. Encapsulation efficiencies were calculated according to the equation:

$$
\% \text { Efficiency }=\frac{(\mathrm{TA}-\mathrm{SA})}{\mathrm{TA}} \times 100 \%
$$

\subsection{Antimicrobial properties}

The bacterial and fungal stock cultures were incubated for $24 \mathrm{hrs}$ at $37^{\circ} \mathrm{C}$ and $48 \mathrm{hrs}$ at $28^{\circ} \mathrm{C}$ on trypticase soy agar and potato dextrose agar (PDA) medium, respectively. The bacterial strains were grown in Mueller-Hinton agar (MHA) plates at $37^{\circ} \mathrm{C}$ (the bacteria were grown in the nutrient broth at $37^{\circ} \mathrm{C}$ at 24 hrs before being transferred into Mueller-Hinton broth), whereas the yeasts and moulds were grown in PDA at $28^{\circ} \mathrm{C}$ (the fungi were grown in Mueller-Hinton broth at room temperature for $24 \mathrm{hrs}$ ) respectively (Bhalodia and Shukla, 2011). Preliminary antimicrobial tests were carried out by agar well diffusion test. The test extracts were sterilized using $0.22 \mu \mathrm{m}$ Millipore filter. Concurrently, the suspension was equivalent to the turbidity 0.5 MacFarland standard prepared from subculture Mueller-Hinton broth for bacteria and fungi respectively. Then, $100 \mu \mathrm{L}$ of bacterial suspension was spread on Mueller-Hinton agar in sterilized Petri dishes. Test extracts of $50 \mu \mathrm{L}$ were added to the wells that were being cut out by sterile tip. Reference antibiotics, chloramphenicol $(30 \mu \mathrm{g} / \mathrm{disc})$ and meropenem $(10 \mu \mathrm{g} /$ disc) were served as positive control for bacteria and fungi, respectively, while the solvent (distilled water, 50 $\mu \mathrm{L})$ was used as a negative control. After that, the inoculated plates were incubated at $37^{\circ} \mathrm{C}$ Antibacterial and antifungal activities were evaluated by measuring the inhibition zone (in $\mathrm{mm}$ ) against the test bacterial strains (Bhalodia and Shukla, 2011).

\subsection{Statistical analysis}

The data was collected and analysed using one-way variance (ANOVA) with multiple comparisons and the 
significant difference $(\mathrm{p}<0.05)$ data were further analysed using Fisher's least test at 95\% confidence intervals. The data were analysed using Minitab 18 software and all data obtained were presented at mean \pm standard deviation.

\section{Results and discussion}

\subsection{Morphology structure}

Figure 1 illustrates the images of gelatine encapsulated $C$. ternatea flowers powder with 350x magnification. All samples exhibited somewhat unique shapes and structures. The particle size of the diameter of the ultrasonic spray dry powders was recorded in the 5$30 \mu \mathrm{m}$ range and was mostly spherical with a smooth and symmetrical shape. However, these results are in contrast with Wang (2015), who stated that spray dried gelatine powder had rough and dimpled surface but spherical in shape. This could be caused by the samples from ultrasonic spray dryer has a high density so they can become sufficiently rigid in quick time (Febriyenti et al., 2014). The convection oven dried powders showed somewhat irregular, amorphous shape and uniform distribution with wrinkled surface in which they had approximately $500-1000 \mu \mathrm{m}$ in diameter. The heat was penetrated through the encapsulating agents in convection drying, resulting in a disturbance that can change the structure. The oven drying procedure can change the well-organized cell structure and the apple tissue intercellular space into broken cell walls, decrease intercellular contact and collapse of cell structure (Xiao and Gao, 2012). Figure 1 also shows that the freeze dried powders demonstrated fibrilar structure with 'collapsebuilding' shape in which they had approximately $0.2-0.7$ $\mathrm{mm}$ particle size in diameter (Qiang et al., 2013; Hau et al., 2018). The freeze dried powders can be described as high porosity with thinner pore walls due to the swelling behaviour of gelatine as encapsulated materials (Jones et al., 2011).

\subsection{Colour profile}

The results showed that the luminosity of freeze dried gelatine encapsulated $C$. ternatea flowers powder exhibited the highest $\mathrm{L}^{*}$ value followed by convection oven and ultrasonic spray dried powders. Similar results were reported by Kang et al. (2014) that the highest L* value had been observed in freeze dried agrooligosaccharide powder. This is because freeze drying removes water by sublimation of ice during freeze drying process at low temperature. Besides that, freeze drying can inhibit oxidation and other chemical reaction, thus minimal colour deterioration (Ratti, 2001). L* values of convection oven powders were higher than ultrasonic spray dried powders due to the differences of temperature used in both encapsulating methods as convection oven dried samples at $80^{\circ} \mathrm{C}$ while ultrasonic spray dried samples at $100^{\circ} \mathrm{C}$. This was due to nonenzymatic browning was promoted under high temperature, resulting in a greater decrease of $\mathrm{L}^{*}$ value (Valentina et al., 2016).

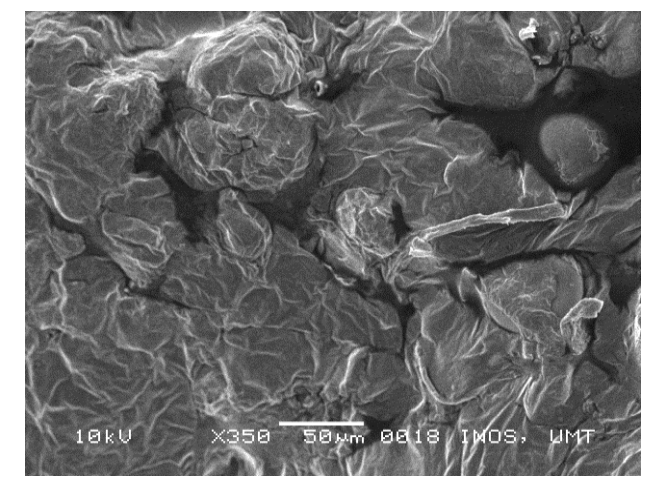

B

A

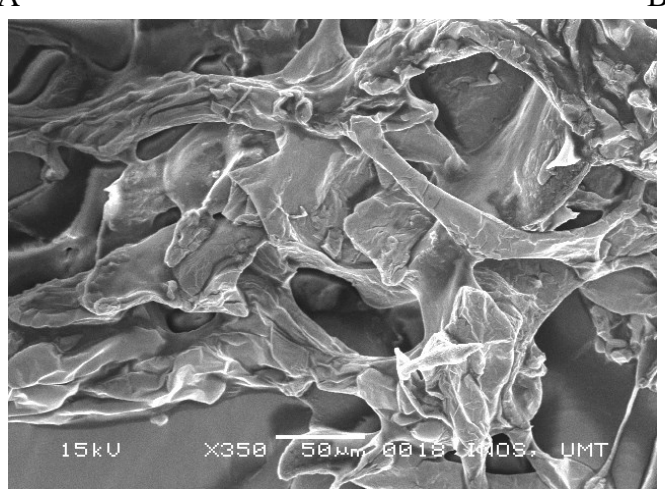

$\mathrm{C}$

Figure 1. Scanning electron microscope (SEM) images of gelatine encapsulated C. ternatea flowers powder with $350 \mathrm{X}$ magnification. $\mathrm{A}=$ Ultrasonic spray dryer, $\mathrm{B}=$ Convection oven and $\mathrm{C}=$ Freeze dryer 
The $a^{*}$ and $b^{*}$ values of the powders were also significantly $(p<0.05)$ affected by encapsulating methods. The positive value of $a^{*}$ demonstrated redness thus a* values from 4.93 to 23.90 indicated a trend of redness from samples of convection oven to ultrasonic spray dryer while the positive value of $b^{*}$ showed yellowness but the only sample from convection oven illustrated yellow colour as it showed a positive value of $b^{*}$ (1.15). Low positive $a^{*}$ value and $b^{*}$ value for samples from convection oven might due to the Maillard reaction had occurred in the condition of high temperature, high moisture contents and long period of time as it can cause the formation of pyruvaldehyde and diacetyl from hydroxymethylfurfural (HMF) in the intermediate stage. Therefore, samples from this stage were slightly yellow or colourless (Tamanna and Mahmood, 2015).

Chroma indicates the colour intensity of saturation $\left(\right.$ chroma $\left.=\left(a^{\circ 2}+b^{\circ 2}\right)^{1 / 2}\right)$ in the samples. Table 1 also illustrated that ultrasonic spray dryer showed the highest chroma values followed by freeze dryer and convection oven. So, the colour for samples from ultrasonic spray dryer was vivid than other encapsulating methods. This could be because ultrasonic spray drying can entrap "active materials" within a protective matrix which is essentially inert to the material being encapsulated (Luz et al., 2007).

Hue angle indicates darkness (hue $=\tan ^{-1}\left(\mathrm{~b}^{*} / \mathrm{a}^{*}\right)$ ). The hue angle denoted negative sign for ultrasonic spray dryer and freeze dryer while the positive sign for convection oven. According to Bahloul et al. (2009), the increase in hue angle is indicative of browning reaction as a result of the activity of polyphenolic oxidase. Likewise, the formation of brown compounds may be as a result of Maillard reaction which occurs upon the reduction of sugar and amino acids (Carabasa-Giribet and Ibarz-Ribas, 2000).

\subsection{Functional groups}

Most of the spectrum from ultrasonic spray dried, convection oven dried and freeze dried powders had slight differences on its peaks respectively but no big changes on peak's wavelength and percentage of transmitted IR means that different encapsulating methods had same functional groups (Table 2). Although there were no big changes in the peak's position and percentage of transmitted IR, there were huge differences of intensities for peak absorbance No. 3 and No. 4 (Figure 2). According to Munajad et al. (2018), the intensities for peak absorbance was correlated with the temperature. The intensities for peak No. 3 and No. 4 for freeze dried samples exhibited the highest amount, followed by ultrasonic spray dried samples while the convection oven dried powders illustrated the lowest intensities for peak No. 3 and No. 4. The intensity for peak absorbance No. 3 might be related to the deformation of $\mathrm{OH}$ group. The reduction of molecular weight of phenolic compounds occurred due to the breakage of hydrogen bonds during deformation of $\mathrm{OH}$ groups. These results were in agreements with the report Bandara et al. (2016) who demonstrated that the occurrence for the reduction of the intensity of $\mathrm{O}-\mathrm{H}$ functional groups for paper aged in mineral oils was due to the breakage of hydrogen bonds in cellulose thus lead to the reduction of molecular weight or degree of polymerization of cellulose. The intensity for peak absorbance No. 4 might correlate to C-O functional groups. Socrates (1997) and Nakanishi and Solomon (1977), the C-O functional groups of ester, carboxylic acid and ether was easily affected by the $\mathrm{C}-\mathrm{O}$ functional groups in the environment. Furthermore, the spectral region for peak absorbance No. 4 was related to flavonoids linked to carbohydrates. Thus, heating the carbohydrates at high temperature and neutral $\mathrm{pH}$ might cause the occurrence of sugar degradation (Woo et al., 2015). So, the occurrence of sugar degradation for both ultrasonic spray dried and convection oven dried powders might result the lower intensities for peak absorption No. 3 and No. 4. This illustrated that heating can somewhat damage the phenolic compounds and flavonoid contents of samples.

\subsection{Moisture contents}

Table 3 shows that the highest moisture contents were obtained in the powders prepared using convection oven with $14.33 \%$, followed by freeze dryer and ultrasonic spray dryer with the lowest moisture contents $(7.28 \%)$ and $(5.94 \%)$. The data collected for the moisture contents of ultrasonic spray dried powders were in accordance to the study by Pettinato et al. (2017) who

Table 1. Colour parameter of gelatine encapsulated $C$. ternatea flowers powder using different encapsulating methods

\begin{tabular}{ccccccc}
\hline \multirow{2}{*}{ Encapsulating methods } & \multicolumn{5}{c}{ Colour parameter } & \multirow{2}{*}{ Colour name } \\
\cline { 2 - 6 } & $\mathrm{L}^{*}$ & $\mathrm{a}^{*}$ & $\mathrm{~b}^{*}$ & Chroma & Hue & \\
\hline Ultrasonic spray dryer & $25.60 \pm 0.02^{\mathrm{c}}$ & $23.90 \pm 0.02^{\mathrm{a}}$ & $-25.13 \pm 0.03^{\mathrm{c}}$ & $34.69 \pm 0.04^{\mathrm{a}}$ & $-46.43 \pm 0.00^{\mathrm{b}}$ & Violet purple $^{\mathrm{a}}$ \\
Convection oven & $39.76 \pm 1.51^{\mathrm{b}}$ & $4.93 \pm 0.93^{\mathrm{c}}$ & $1.15 \pm 0.23^{\mathrm{a}}$ & $5.17 \pm 0.75^{\mathrm{c}}$ & $12.63 \pm 3.64^{\mathrm{a}}$ & Reddish-orange $^{\mathrm{b}}$ \\
Freeze dryer & $45.62 \pm 0.54^{\mathrm{a}}$ & $11.8 \pm 0.18^{\mathrm{b}}$ & $-8.84 \pm 1.61^{\mathrm{b}}$ & $14.77 \pm 1.11^{\mathrm{b}}$ & $-36.67 \pm 4.54^{\mathrm{b}}$ & Magenta \\
\hline
\end{tabular}

All values given are means of triplicate results. Standard deviation (mean \pm SD) is included for each average. Means with different letter are significantly different at $\mathrm{p}<0.05$. 


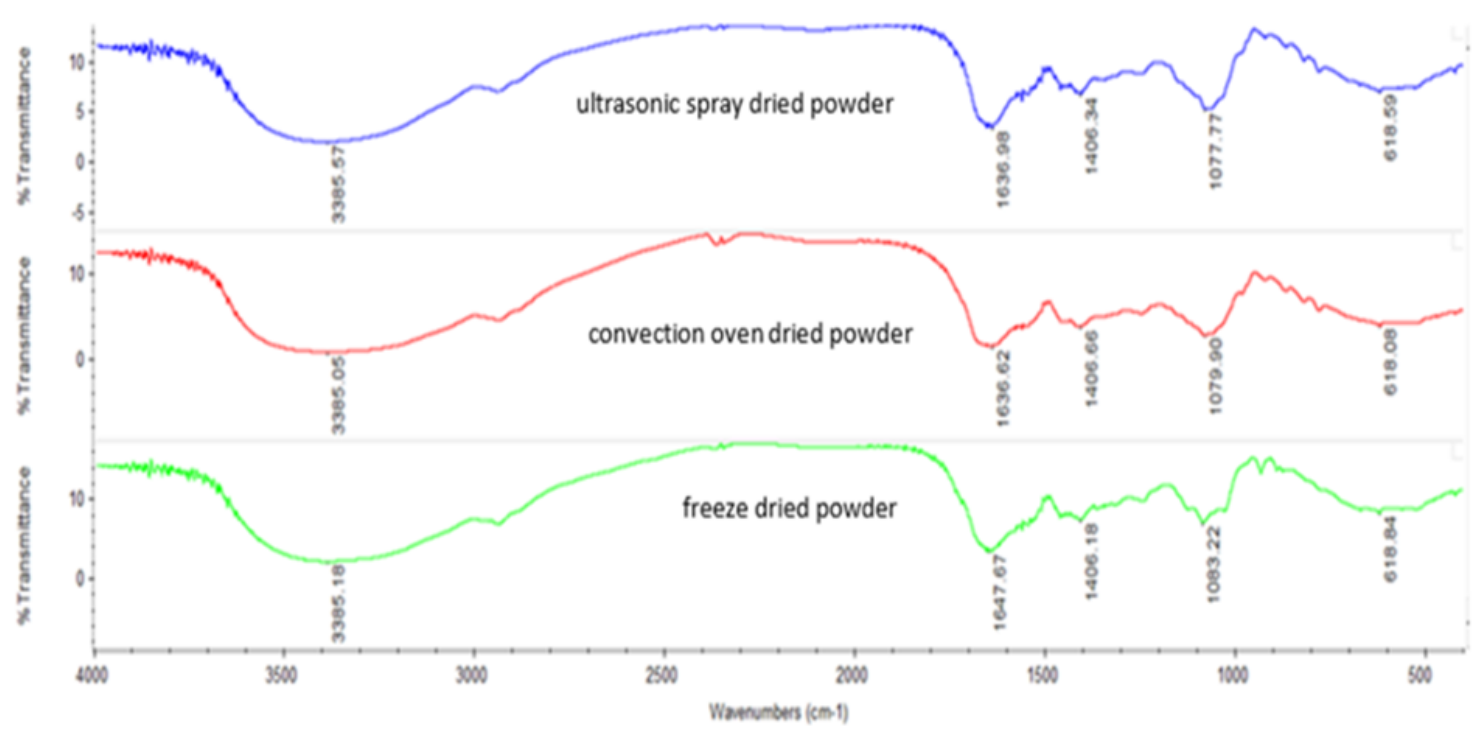

Figure 2. FTIR spectra of functional groups present in C. ternatea flower powders (blue: ultrasonic spray dried powder, red: convection oven dried powder and green: freeze dried powder)

Table 2. Peak intensity and functional group for the ultrasonic spray dried, convection oven dried, freeze dried gelatine encapsulated $C$. ternatea flowers powder

\begin{tabular}{|c|c|c|c|c|c|}
\hline No & Wavenumber $\left(\mathrm{cm}^{-1}\right)$ & Frequency ranges & Assignment & Functional group & Peak \\
\hline \multicolumn{6}{|c|}{ Ultrasonic spray dried gelatine encapsulated C. ternatea flowers powder } \\
\hline 1 & 3385.57 & $3570-3200$ & H-bonded $\mathrm{OH}$ stretch & Hydroxyl group/alcohol/ phenol & 1.774 \\
\hline 2 & 1636.98 & $1680-1620$ & $\mathrm{C}=\mathrm{C}$ stretch & Alkenes & 3.27 \\
\hline \multirow{3}{*}{3} & \multirow{3}{*}{1406.34} & $1600-1400$ & $\mathrm{C}=\mathrm{C}$ stretch & \multirow{3}{*}{ Aromatics } & \multirow{3}{*}{6.655} \\
\hline & & $1410-1260$ & $\mathrm{OH}$ deformation & & \\
\hline & & $1290-1000$ & $\mathrm{C}-\mathrm{H}$ group in-plane & & \\
\hline \multirow{3}{*}{4} & \multirow{3}{*}{1077.77} & $1300-1000$ & $\mathrm{C}-\mathrm{O}$ stretch & Ester, carboxylic acid and ether & \multirow[b]{2}{*}{5.088} \\
\hline & & & & Pyranose structure (flavonoids linked to & \\
\hline & & $1200-950$ & C-O stretch & & \\
\hline 5 & 618.59 & - & - & - & 6.789 \\
\hline
\end{tabular}

Convection oven dried gelatine encapsulated C. ternatea flowers powder

\begin{tabular}{|c|c|c|c|c|c|}
\hline 1 & 3385.05 & $3570-3200$ & $\mathrm{H}$-bonded $\mathrm{OH}$ stretch & Hydroxyl group/ alcohol/phenol & 0.611 \\
\hline 2 & 1636.62 & $1680-1620$ & $\mathrm{C}=\mathrm{C}$ stretch & Alkenes & 1.299 \\
\hline \multirow{2}{*}{3} & \multirow{2}{*}{1406.66} & $1600-1400$ & $\mathrm{C}=\mathrm{C}$ stretch & \multirow{2}{*}{ Aromatics } & \multirow{2}{*}{3.607} \\
\hline & & $1410-1260$ & OH deformation & & \\
\hline \multirow{3}{*}{4} & \multirow{3}{*}{1079.9} & $1290-1000$ & $\mathrm{C}-\mathrm{H}$ group in-plane & & \multirow{3}{*}{2.592} \\
\hline & & $1300-1000$ & $\mathrm{C}-\mathrm{O}$ stretch & $\begin{array}{l}\text { Ester, carboxylic acid and ether } \\
\text { Pyranose structure (flavonoids linked to } \\
\text { carbohydrates) }\end{array}$ & \\
\hline & & $1200-950$ & C-O stretch & & \\
\hline 5 & 618.08 & - & - & - & 3.698 \\
\hline
\end{tabular}

Freeze dried gelatine encapsulated C. ternatea flowers powder

\begin{tabular}{|c|c|c|c|c|c|}
\hline 1 & 3385.18 & $3570-3200$ & H-bonded $\mathrm{OH}$ stretch & Hydroxyl group/ alcohol/phenol & 1.861 \\
\hline 2 & 1647.67 & $1680-1620$ & $\mathrm{C}=\mathrm{C}$ stretch & Alkenes & 3.191 \\
\hline \multirow{2}{*}{3} & \multirow{2}{*}{1406.18} & $1600-1400$ & $\mathrm{C}=\mathrm{C}$ stretch & \multirow{3}{*}{ Aromatics } & \multirow{3}{*}{7.197} \\
\hline & & $1410-1260$ & OH deformation & & \\
\hline \multirow{4}{*}{4} & \multirow{4}{*}{1083.22} & $1290-1000$ & $\mathrm{C}-\mathrm{H}$ group in-plane & & \\
\hline & & $1300-1000$ & C-O stretch & Ester, carboxylic acid and ether & \multirow{3}{*}{6.796} \\
\hline & & & & Pyranose structure (flavonoids linked to & \\
\hline & & $1200-950$ & C-O stretch & & \\
\hline 5 & 618.84 & - & - & - & 8.092 \\
\hline
\end{tabular}


reported $5.3 \%$ to $7.0 \%$ of spray dried spent coffee ground sample. However, the moisture contents of freeze dried powders were $7.28 \%$ was a little bit difference than freeze dried $C$. ternatea flowers powders encapsulated with $100 \%$ Arabic gum, 50\% Arabic gum with $50 \%$ maltodextrin and $100 \%$ maltodextrin with the range of $6.5 \%$ to $7.2 \%$ moisture contents as reported by Hamzah et al. (2013). The differences may due to the different encapsulating agents used in this study. Thus, the moisture contents for freeze dried samples were recorded higher than previous studies. The moisture contents for convection oven dried powders showed the highest (14.33\%). The results collected were different as reported by Ali et al. (2016), who demonstrated that the moisture contents for guava slices that dried in the convection oven for $4.5 \mathrm{hrs}$ at $80^{\circ} \mathrm{C}$ were $7.15 \%$. The differences may due to the different drying samples and different duration time for drying the sample.

\subsection{Total flavonoid contents}

The total flavonoid contents of the ultrasonic-spray dried sample exhibited the highest amount followed by freeze-dried sample and convection-oven-dried sample (Table 3). This shows that the technique, as well as temperature, greatly influence the total flavonoid contents in the sample. These results were similar with spray dried papaya products presented higher retention of flavonoids as compared with the freeze dried papaya products (Gomes et al., 2018). This could also be due to the formation of microcapsules at the final stage during entrapment of high incidence of extract contents by ultrasonic spray drying (Chen et al., 2013).

Table 3 also shows that the freeze dried sample exhibited the second-highest flavonoids content among the encapsulating methods. This might due to the absence of some components during flavonoid biosynthesis. According to Buchner et al. (2006), chalcones and isoflavones cannot be synthesized naturally but they can produce after being stress. Besides that, freeze drying also can cause inconsistently entrapment of extract contents thus leads to a decrease in total flavonoid contents (Dickinson, 2003).

The samples dried using the convection oven exhibited the lowest flavonoid contents as heating can block most flavonoid biosynthesis. These results were in accordance with the results reported by Zhang et al. (2019) that rapid oven drying at $75^{\circ} \mathrm{C}$ can destroy enzyme activity and block the synthesis pathway of flavonoids. Besides that, Zhang et al. (2019) also proved that the presence of only four components from flavonoid biosynthesis (scutellarein 7-O-glucobioside, apigenin 7-O-rutinoside, apigenin-C-pentoside, and kaempferol 3-O- $\alpha$-L-arabinopyranoside) after direct heating at $75^{\circ} \mathrm{C}$ as these components were unaffected by the drying pre-treatments.

\subsection{Total anthocyanin contents}

Table 3 indicates that the total anthocyanin content found to be higher in ultrasonic spray dried treatment, followed by oven-dried treatment and freeze dried treatment. This result was found to be in contrast with total anthocyanin contents for freeze dried rose (Rosa rugose) was higher than spray dried powders ( $\mathrm{Yu}$ and Lv, 2019). This might due to different morphology structure produced from the different sample but the same drying technique. The freeze dried rose powder as shown by $\mathrm{Yu}$ and $\mathrm{Lv}$ (2019) had an indefinite and laminate structure that the compact brittle textures with prominently sharp edges but the freeze dried samples showed fibrillar structure and 'collapse-building' shape. In the current study, the fibrillar structure and 'collapsebuilding' sample form of the freeze dryer was not as successful in preserving anthocyanin compared to the previous research (Hau et al., 2018). In addition, the irregular, rough and dimpled surface of convection oven dried powders had low anthocyanin contents. This might because the shrivelled surface can affect the stability of anthocyanin contents thus resulting in the faster anthocyanin degradation during storage (Ferrari et al., 2013). The roughened surface and cavities of powders

Table 3. Moisture contents, total flavonoid contents, total anthocyanin contents, encapsulation efficiency, Inhibition of DPPH of gelatine encapsulated $C$. ternatea flowers powder prepared using different encapsulating methods

\begin{tabular}{lccccc}
\hline & $\begin{array}{c}\text { Moisture } \\
\text { contents }(\%)\end{array}$ & $\begin{array}{c}\text { Total flavonoid } \\
\text { contents }(\mu \mathrm{g} \\
\text { quercetin/100 mg) }\end{array}$ & $\begin{array}{c}\text { Total anthocyanin } \\
\text { contents }(\mathrm{mg} \\
\text { delphinidin-3-O- } \\
\text { sambuboside/100 mg) }\end{array}$ & $\begin{array}{c}\text { Encapsulation } \\
\text { efficiency }(\%)\end{array}$ & $\begin{array}{c}\text { Inhibition of } \\
\text { DPPH }(\%)\end{array}$ \\
\hline ultrasonic spray dried & $5.94 \pm 0.08^{\mathrm{b}}$ & $145.24 \pm 2.44^{\mathrm{a}}$ & $1.58 \pm 0.14^{\mathrm{a}}$ & $60.22 \pm 0.75^{\mathrm{b}}$ & $18.89 \pm 2.32^{\mathrm{e}}$ \\
convection oven dried & $14.33 \pm 1.21^{\mathrm{a}}$ & $24.05 \pm 1.32^{\mathrm{c}}$ & $0.55 \pm 0.02^{\mathrm{b}}$ & $63.38 \pm 1.64^{\mathrm{b}}$ & $23.78 \pm 1.54^{\mathrm{d}}$ \\
freeze dried & $7.28 \pm 1.02^{\mathrm{b}}$ & $45.24 \pm 1.12^{\mathrm{b}}$ & $0.78 \pm 0.01^{\mathrm{b}}$ & $95.74 \pm 0.05^{\mathrm{a}}$ & $37.78 \pm 3.32^{\mathrm{c}}$ \\
Ascorbic acid & - & - & - & - & $92.11 \pm 3.58^{\mathrm{a}}$ \\
$\alpha$-tocopherol & - & - & - & - & $41.67 \pm 3.87^{\mathrm{c}}$ \\
BHT & - & - & - & $67.89 \pm 5.52^{\mathrm{b}}$ \\
\hline
\end{tabular}

All values given are means of triplicate results. Means with different letter are significantly different at $\mathrm{p}<0.05$. 
were due to the rapid water evaporation during drying in convection oven (Bernstein and Noreña, 2015). The anthocyanin contents for samples from convection oven was lower might due to the penetration of heat through the encapsulating agents thus causing anthocyanin degradation. The results of total anthocyanin contents for Yu and Lv (2019) was in contrast with the current study might due to the different encapsulating agents used from the same drying technique (freeze dryer).

\subsection{Antioxidative activity using 2,2-diphenyl-2- picrylydrazyl (DPPH) assay}

The freeze dried powders showed the strong inhibition of 2,2-diphenyl-2-picrylydrazyl (DPPH) radicals, which was significantly higher than other samples (Table 3). The stresses provided by the differences in drying technique as well as drying temperature. This results in concert with the report of $\mathrm{Yu}$ et al. (2018), who demonstrated that the freeze dried raspberry was higher than spray dried raspberry because higher drying temperatures caused a bigger decrease in DPPH free radical scavenging capacity. This might also due to the presence of other phenolic compounds in freeze dryer although its total flavonoid contents and total anthocyanin contents were lower than ultrasonic spray dryer. The anthocyanin degradation products demonstrated higher antioxidant activity. This was due to the application of heat will promote the cleavage of acylated anthocyanins into their corresponding acylglucosides, then into intermediate chalcones (phenolic acids and aldehydes) that contributed to an increase of antioxidant activity in the samples. A similar phenomenon had been observed for purple potato that anthocyanin degradation can contribute to the increase of antioxidant activity (Nayak et al., 2011). However, the antioxidant activity for all samples was comparable to the standard and only the freeze dried powders were not significantly different between $\alpha$-tocopherol and samples but it also lower than $\alpha$-tocopherol.

\subsection{Encapsulation efficiency (anthocyanin contents)}

Table 3 also exhibits the encapsulation efficiency based on anthocyanin contents for freeze dried powders was found to be highest $(95.74 \%)$, followed by convection oven $(63.38 \%)$ and ultrasonic spray dryer $(60.22 \%)$. Ironically, the total anthocyanin contents of ultrasonic spray dried powders was the highest with the lowest encapsulation efficiency. The results were in agreement with El-Messery et al. (2019), who stated that the technique for spray drying and ultraturax had lower encapsulation efficiency than freeze drying and ultrasonication. In contrast, freeze drying allows dropletto-droplet interaction in the extract until the drying stage and this leads to higher consumption of time than spray drying, resulting in an inconsistency in the entrapment of the extract of the freeze-dried encapsulated powder which leads to a low incidence of entrapment of extract content and thereby, a high surface content. In addition, the atomization of the feed materials by spray drying can result in very fine mist-like droplets with increased surface area. Increase in surface area means more exposure to heat. Further, there may be instances when due to atomization some part of the coating material could get removed from the core material even after homogenisation.

\subsection{Antimicrobial and antifungal properties}

Table 4 shows all foodborne pathogenic bacteria and fungi were inhibited by freeze dried $C$. ternatea flowers. $A$. niger showed was the most affected fungi followed by C. albicans. In terms of foodborne pathogenic bacteria, $B$. cereus, $S$. enterica illustrated higher inhibition zone among bacteria while $E$. coli and $S$. aureus demonstrated the lowest inhibition zone. The diameter of clear zones illustrated the different susceptibility of bacteria to the extracts (Leong et al., 2017). The antimicrobial effect for $S$. enterica and B. cereus were better than E. coli and $S$. aureus proving that freeze dried $C$. ternatea flowers were able to retard Gram-positive bacteria as well as Gram-negative bacteria. These results were similar to reports of Kamilla and co-workers (2009) that $S$. enterica serovar Typhi, B. cereus, E. coli and S. aureus were inhibited by $C$. ternatea flowers methanolic extracts. The lowest inhibition zone can be shown by $E$. coli and $S$.

Table 4. Antimicrobial and antifungal activity for freeze dried gelatine encapsulated C. ternatea flowers powder (100.00 mg/ $\mathrm{mL}$ ), positive and negative control against foodborne pathogenic bacteria and fungi

\begin{tabular}{ccccc}
\hline \multirow{2}{*}{$\begin{array}{c}\text { Foodborne bacteria and } \\
\text { fungi }\end{array}$} & $\begin{array}{c}\text { Freeze dried C. ternatea } \\
\text { flowers }\end{array}$ & \multicolumn{2}{c}{ Negative control } & \multicolumn{2}{c}{ Positive control } \\
\cline { 3 - 5 } E. coli & $10.67 \pm 1.18^{\mathrm{c}}$ & Sterile distilled water & Chloramphenicol & Meropenem \\
\hline S. aureus & $9.42 \pm 0.12^{\mathrm{c}}$ & $\mathrm{NI}$ & $25.09 \pm 2.24^{\mathrm{a}}$ & - \\
B. cereus & $16.92 \pm 1.77^{\mathrm{b}}$ & $\mathrm{NI}$ & $24.84 \pm 0.23^{\mathrm{a}}$ & - \\
S. enterica & $17.00 \pm 0.71^{\mathrm{b}}$ & $\mathrm{NI}$ & $22.84 \pm 1.65^{\mathrm{a}}$ & - \\
A. niger & $22.00 \pm 0.71^{\mathrm{a}}$ & $\mathrm{NI}$ & - & - \\
C. albicans & $18.09 \pm 2.00^{\mathrm{b}}$ & $\mathrm{NI}$ & - & $35.75 \pm 0.59^{\mathrm{a}}$ \\
\hline
\end{tabular}

All values given are means of triplicate results. Means with different letter are significantly different at $\mathrm{p}<0.05$. 
aureus might due to the difference's resistance of bacteria against antibiotics.

\section{Conclusion}

This study proved that freeze dried powders exhibited the best encapsulating methods due to its high encapsulation efficiency and antioxidant activity with moderately high total flavonoid contents, low total anthocyanin contents and moisture contents. FTIR analysis also revealed the presence of highest amounts of phenolic compounds in freeze dried samples although it showed irregular shape like "collapse building" with fibrillar structure. For antimicrobial properties, the freeze dried powders were effective against all tested bacteria (S. aureus, E. coli, S. enterica and B. cereus) and tested fungi (A. niger and C. albicans).

\section{Conflict of Interest}

The authors declare no conflict of interest

\section{Acknowledgement}

This research was supported by Universiti Malaysia Terengganu. The authors would like to thank the UMT's central lab and FPSM for the facilities provided to conduct the study.

\section{References}

Ali, M.A., Yusof, Y.A., Chin, N.L. and Ibrahim, M.N. (2016). Effect of different drying treatments on colour quality and ascorbic acid concentration of guava fruit. International Food Research Journal, 23 (Suppl. 1), S155-S161.

AOAC International. (2007). Official Methods of Analysis of AOAC International. AOAC Official Method 990.26. $17^{\text {th }}$ ed. Gaithersburg, MD. USA: AOAC International.

Arslan, D. and Ózcan, M.M. (2010). Study the effect of sun, oven and microwave drying on quality of onion slices. LWT - Food Science and Technology, 43(7), 1121-1127. https://doi.org/ 10.1016/ j.lwt.2010.02.019.

Bahloul, N., Boudhrioua, N., Kouhila, M. and Kechaou, N. (2009). Effect of convective solar drying on colour, total phenols and radical scavenging activity of olive leaves (Olea europaea L.). International Journal of Food Science and Technology, 44(12), 2561-2567. https://doi.org/10.1111/j.13652621.2009.02084.x.

Bandara, K., Ekanayake, C., Saha, T.K. and Annamalai, P.K. (2016). Understanding the ageing aspects of natural ester based insulation liquid in power transformer. IEEE Transactions on Dielectrics and Electrical Insulation, 23(1), 246-257. https:// doi.org/10.1109/tdei.2015.004744.

Begum, Y.A. and Deka, S.C. (2017). Stability of spraydried microencapsulated anthocyanins extracted from culinary banana bract. International Journal of Food Properties, 20(12), 3135-3148. https:// doi.org/10.1080/10942912.2016.1277739.

Bernstein, A. and Noreña, C.P.Z. (2015). Encapsulation of Red Cabbage (Brassica oleracea L. var. capitata L. f. rubra) anthocyanins by spray drying using different encapsulating agents. Brazilian Archives of Biology and Technology, 58(6), 944-952. http:// dx.doi.org/10.1590/S1516-89132015060226.

Bhalodia, N.R. and Shukla, V.J. (2011). Antibacterial and antifungal activities from leaf extracts of Cassia fistula L., An ethnomedicinal plant. Journal of Advanced Pharmaceutical Technology and Research, 2(2), 104-109. https:// doi.org/10.4103/2231-4040.82956.

Buchner, N., Krumbein, A., Rohn, S. and Kroh, L.W. (2006). Effect of thermal processing on the flavonols rutin and quercetin. Rapid Communications in Mass Spectrometry, 20(21), 3229-3235. https:// doi.org/10.1002/rcm.2720.

Carabasa-Giribet, M. and Ibarz-Ribas, A. (2000). Kinetics of colour development in aqueous glucose systems at high temperatures. Journal of Food Engineering, 44(3), 181-189. https:// doi.org/10.1016/S0260-8774(00)00027-3.

Chen, Q., Zhong, F., Wen, J., McGillivray, D. and Quek, S.Y. (2013). Properties and stability of spray-dried and freeze-dried microcapsules co-encapsulated with fish oil, phytosterol esters, and limonene. Drying Technology, 31(6), 707-716. https:// doi.org/10.1080/07373937.2012.755541.

Collins, R. and Grundy, T. (2005). The butterfly pea book. A guide to establishing and managing butterfly pea pastures in central Queensland. $1^{\text {st }}$ ed. Queensland, DPI and F Publications, 8-9.

Dickinson, E. (2003). Hydrocolloids at interfaces and the influence on the properties of dispersed systems. Food Hydrocolloids, 17(1), 25-39. https:// doi.org/10.1016/S0268-005X(01)00120-5.

El-Messery, T.M., El-Said, M.M., Demircan, E. and Ozçelik, B. (2019). Microencapsulation of natural polyphenolic compounds extracted from apple peel and its application in yoghurt. Acta Scientiarum Polonorum Technologia Alimentaria, 18(1), 25-34. https://doi.org/10.17306/J.AFS.2019.0597.

Fang, Z. and Bhandari, B. (2010). Encapsulation of polyphenols-a review. Trends in Food Science and 
Technology, 21(10), 510-523. https:// doi.org/10.1016/j.tifs.2010.08.003.

Febriyenti, F, Mokhtar, N., Mohamed, N., Hamdam, M.R., Md Salleh, S.N. and Bal @ Bale, S. (2014). Comparison of freeze drying and spray drying methods of Haruan extract. International Journal of Drug Delivery, 6, 286-291.

Ferrari, C.C., Germer, S.P.M., Alvin, I.D. and Aguirre, J.M. (2013). Storage stability of spray-dried blackberry powder produced with maltodextrin or gum arabic. Drying Technology, 31(4), 470-478. https://doi.org/10.1080/07373937.2012.742103.

Gomes, W.F., França, F.R.M., Denadai, M., Andrade, J.K.S., da Silva Oliveira, E.M., de Brito, E.S. and Narain, N. (2018). Effect of freeze and spray-drying on physico-chemical characteristics, phenolic compounds and antioxidant activity of papaya pulp. Journal of Food Science and Technology, 55(6), 2095-2102. https://doi.org/10.1007/s13197-018-3124 $-\mathrm{Z}$.

Hamzah, Y., Jumat, N.A., Zaliha, W. and Sembok, W. (2013). Effect of drying on the storage stability of encapsulated anthocyanins powder extract from Butterfly Pea flower (Clitoria ternatea). In 13th ASEAN Food Conference, towards Meeting Future Food Demands, Security and Sustainability, 9-11 September 2013, p. 1-10. Singapore.

Hau, E. H., Mohd Zin, Z., Zuraidah, N., Shaharudin, N.A. and Zainol, M.K. (2018). Physicochemical properties of powdered protein hydrolysate Yellowstripe scald (Selaroides leptolepis) fish. International Food Research Journal, 25(6), 25532559.

Jones, R.J., Rajabi-Siahboomi, A., Levina, M., Perrie, Y. and Mohammed, A.R. (2011). The influence of formulation and manufacturing process parameters on the characteristics of lyophilized orally disintegrating tablets. Pharmaceutics, 3(3), 440-457.

Kaisoon, O., Siriamornpun, S., Weerapreeyakul, N. and Meeso, N. (2011). Phenolic compounds and antioxidant activities of edible flowers from Thailand. Journal of Functional Foods, 3(2), 88-99. https://doi.org/10.1016/j.jff.2011.03.002.

Kamilla, L., Mnsor, S.M., Ramanathan, S. and Sasidharan, S. (2009). Antimicrobial activity of Clitoria ternatea (L.) Extracts. Pharmacologyonline, 1, 731-738.

Kang, O.L., Yong, P.F., Ma'aruf, A.G., Osman, H. and Nazaruddin, R. (2014). Physicochemical and antioxidant studies on oven-dried, freeze-dried and spray-dried agaro-oligosaccharide powders. International Food Research Journal, 21(6), 2363-
2367.

Karim, A.A. and Bhat, R. (2008). Gelatine alternatives for the food industry, recent developments, challenges and prospects. Trends in Food Science and Technology, 19(12), 644-656. https:// doi.org/10.1016/j.tifs.2008.08.001.

Leong, C.-R., Kamarul Azizi, M.A., Taher, M.A., Wahidin, S., Lee, K.-C., Tan, W.-N. and Tong, W.Y. (2017). Anthocyanins from Clitoria ternatea attenuate food-borne Penicillium expansum and its potential application as food biopreservative. Natural Product Science, 23(2), 125-131. https:// doi.org/10.20307/nps.2017.23.2.125.

Luz, P.P., Pires, A.M. and Serra, O.A. (2007). A lowcost ultrasonic spray dryer to produce spherical microparticles from polymeric matrices. Química Nova, 30(7), 1744-1746. http://dx.doi.org/10.1590/ S0100-40422007000700041.

Munajad, A., Subrato, C. and Suwarno (2018). Fourier Transform Infrared (FTIR) spectroscopy analysis of transformer paper in mineral oil-paper composite insulation under accelerated thermal aging. Energies, 11(364), 1-12. https://doi.org/10.3390/en11020364.

Nair, V., Bang, W.Y., Schreckinger, E., Andarwulan, N. and Zevallos, C. (2015). Protective role of ternatin anthocyanins and quercetin glycosides from Butterfly Pea (Clitoria ternatea Leguminosae) blue flower petals against lipopolysaccharide (LPS) induced inflammation in macrophage cells. Journal of Agricultural and Food Chemistry, 63(28), 63556365. https://doi.org/10.1021/acs.jafc.5b00928.

Ng, K.S., Mohd Zin, Z., Mohd Maidin, N., Abdullah, M.A.A. and Zainol, M.K. (2020). Effect of steaming time on antioxidant properties of Napier grass herbal tea by green tea processing method. Food Research, 4(1), 175-183. https://doi.org/10.26656/fr.2017.4 (1).263.

Nakanishi, K. and Solomon, P.A. (1977). Infrared absorption spectroscopy. $2^{\text {nd }}$ ed. San Francisco, Holden-Day.

Nayak, B., Berrios, J.D.J., Powers, J.R. and Tang, J. (2011). Thermal degradation of anthocyanins from purple potato ( $\mathrm{cv}$. purple majesty) and impact on antioxidant capacity. Journal of Agricultural and Food Chemistry, 59(20), 11040-11049. https:// doi.org/10.1021/jf201923a.

Pa'ee, F., Jamil, N., Mohd Nasim, N.A. and Mohd Zairi, M.N. (2018). Influences of environmental conditions to phytoconstituents in Clitoria ternatea (Butterfly pea flower) - A Review. Journal of Science and Technology, 10(2), 208-228. https:// doi.org/10.30880/jst.2018.10.02.029. 
Pettinato, M., Aliakbarian, B., Casazza, A.A. and Perego, P. (2017). Encapsulation of antioxidants from spent coffee ground extracts by spray drying, Chemical Engineering Transactions, 57, 1219-1224. https://doi.org/10.3303/CET1757204.

Qiang, M.R., Song, L., Chen, F.H., Li, M.Z., Liu, X.X. and Wang, Q. (2013). A 16-ka lake-level record inferred from macrofossils in a sediment core from Genggahaii Lake, North-eastern Qinghai-Tibetan Plateau (China). Journal of Paleolimnology, 49, 575590.

Rajan, R. and Pandit, A.B. (2001). Correlations to predict droplet size in ultrasonic atomisation. Ultrasonics, 39(4), 235-255. https://doi.org/10.1016/ s0041-624x(01)00054-3.

Ratti, C. (2001). Hot air and freeze-drying of high-value foods, a review. Journal of Food Engineering, 49(4), 311-319. https://doi.org/10.1016/S0260-8774(00) 00228-4.

Sivarajan, V.V. and Balachandran, I. (1994). Ayurvedic drug and their plant sources. Oxford and IBH, 425428.

Socrates, G. (1995). Infrared characteristic group frequencies, tables and charts. Journal of the American Chemical Society, 117(5), 1671-1671.

Soysal, Y. and Oztekin, S. (2001). Technical and economic performance of a tray dryer for medicinal and aromatic plants. Journal of Agricultural Engineering Research, 79(1), 73-79. https:// doi.org/10.1006/jaer.2000.0668.

Sukwattaansinit, T., Burana-Osot, J. and Sotanaphun, U. (2016). Simple and rapid spectrophotometric method for quality determination of roselle (Hibiscus sabdariffa). Thai Journal of Pharmaceutical Sciences, 40(4), 194-199.

Talegaonkar, S., Pandey, S., Rai, N., Rawat, P., Sharma, H. and Kumari, N. (2016). Exploring nanoencapsulation of aroma and flavours as new frontier in food technology. In Grumezescu, A.M. (Eds.) Encapsulation., p. 47-88. USA: Elsevier

Tamanna, N. and Mahmood, N. (2015). Food processing and Maillard reaction products, effect on human health and nutrition. International Journal of Food Science, 2015, 1-6. https:// doi.org/10.1155/2015/526762.

Valentina, V., Pratiwi, A.R., Hsiao, P.Y., Tseng, H.T., Hsieh, J.F. and Chen, C.C. (2016). Sensorial Characterization of Foods Before and After Freezedrying. Austin Food Sciences, 1(6), 1027.

Wang, B.P. (2015). Development of spray drying technology for microencapsulation of bioactive materials. Alabama, USA: Auburn University, PhD
Dissertation.

Woo, K.S., Kim, H.Y., Hwang, I.G., Lee, S.H. and Jeong, H.S. (2015). Characteristics of the thermal degradation of glucose and maltose solutions. Preventive Nutrition and Food Science, 20(2), 102109. http://dx.doi.org/10.3746/pnf.2015.20.2.102.

Xiao, H.-W. and Gao, Z.-J. (2012). The application of scanning electron microscope (SEM) to study the microstructure changes in the field of agricultural products drying. Scanning Electron Microscopy. https://doi.org/10.5772/35223.

Yu, J., Shangguan, Z., Yang, X., Sun, D., Zhu, B. and Ouyang, J. (2018). Effect of drying on the bioactive compounds and antioxidant activity of Rubus lambertianus. International Journal of Food Engineering, 14(2), 1-9. https://doi.org/10.1515/ijfe2016-0412.

Yu, Y.J. and Lv, Y.P. (2019). Degradation kinetic of anthocyanins from rose (Rosa rugosa) as prepared by microencapsulation in freeze-drying and spraydrying, International Journal of Food Properties, 22 (1), 2009-2021. https:// doi.org/10.1080/10942912.2019.1701011.

Zainol, M.K., Wern, L.H., Fauzi, N.I.B.M., Shin, N.K., Razman, N., Kadimi, N.F. and Mamat, H. (2017). Antioxidative properties of selected microencapsulated plants powder prepared using ultrasonic spray-drying technique. Malaysian Applied Biology Journal, 46(3), 41-49.

Zainol, M.K., Wong, K.Y., Mohd Zin, Z., Kamarudin, K.S., Danish-Daniel, A., Ng. K.S. and Mamat, H. (2018). Effect of ethanol in ultrasonic assisted extraction technique on antioxidative properties of passion fruit (Passiflora edulis) leaves. Malaysian Applied Biology Journal, 47(6), 19-27.

Zhang, X., Wang, X., Wang, M., Cao, J., Xiao, J. and Wang, Q. (2019). Effects of different pre-treatments on flavonoids and antioxidant activity of Dryopteris erythrosora leave. PloS one, 14(1), e0200174. https://doi.org/10.1371/journal.pone.0200174.

Zielinska, M., Zapotoczny, P., Alves-Filho, O., Eikevik, T.M. and Blaszczak, W. (2013). A multi-stage combined heat pump and microwave vacuum drying of green peas. Journal of Food Engineering, 115(3), 347-356. https://doi.org/10.1016/ j.jfoodeng.2012.10.047. 